\title{
Controverses, complicaties en nieuwe technieken in nierchirurgie
}

\author{
A. H. (Heleen) de Vries · Patricia J. Zondervan · Harrie P. Beerlage
}

\section{Introductie}

Sinds de introductie van minimaal-invasieve chirurgie (MIS) in de jaren '90 van de vorige eeuw heeft de nierchirurgie een enorme vlucht genomen. $\mathrm{Na}$ de eerste laparoscopische nefrectomie in 1990 door Ralph Clayman volgde in 2001 de eerste robotgeassisteerde nefrectomie door Bertrand Guillonneau. Inmiddels wordt in Nederland de nierchirurgie grotendeels minimaal-invasief uitgevoerd.

Is er in dit tijdperk nog ruimte voor open nierchirurgie? Hoe ver gaan we in niersparende chirurgie? Wat zijn de belangrijkste complicaties van nierchirurgie, en wat is het belang van vaardigheidstraining en centralisatie in hoogvolumecentra in het voorkomen hiervan? En tot slot: wat brengt de toekomst? Deze vragen zijn besproken tijdens het EAU20 Virtual. Dit artikel zal hier kort op ingaan.

\section{Controverses in nierchirurgie}

De verschuiving van open naar robotchirurgie: waar ligt de grens?

In de plenaire sessie 'Nightmare on robotics' besprak dr. Larcher een complexe casus van een patiënt met een cT3b-niertumor bij wie een robotgeassisteerde radicale nefrectomie (RARN) met cavotomie en trombectomie werd verricht. De ingreep werd volledig robotgeassisteerd uitgevoerd door een uroloog en werd gecompliceerd door een bloeding uit een niet-geïdentificeerde arterie en lumbaalvene. Hierdoor duurde de operatie ruim vijf uur en trad 3.200 cc bloedverlies op. De patiënt bracht postoperatief tien dagen door op de IC en had kortdurend hemodialyse nodig [1].

Deze casus werd uitgebreid nabesproken door een aantal expert-urologen en mr. Leigh, participerend advo-

\footnotetext{
dr. A. H. (Heleen) de Vries $(\square)$

afdeling Urologie, Amsterdam Universitair Medisch Centrum, locatie VUmc, Amsterdam, Nederland

a.h.devries@amsterdamumc.nl
}

caat. De laatste stelde kritische vragen over de gebruikte benadering ("Had deze complexe ingreep niet direct open moeten worden uitgevoerd?") en over de afwezigheid van een vaatchirurg.

Prof. Schwentner beaamde dat een dergelijke casus in veel centra nog open benaderd zal worden met de assistentie van een vaatchirurg, maar hij was ook van mening dat een ervaren roboturoloog de operatie zelfstandig robotgeassisteerd zou moeten kunnen uitvoeren, mits voldaan wordt aan de volgende sleutelfactoren:

1. Zorgvuldige preoperatieve patiënt planning middels een CT-scan met 3D-reconstructie voor correcte identificatie van de vaatstructuren en collateralen.

2. Een toegewijd operatieteam.

3. Ervaring van de operateur. Niet alleen ervaring met RAPN, maar ook ruime ervaring met open chirurgie is essentieel. Prof. Schwentner benadrukte het belang van ervaring met het verrichten van retroperitoneale lymfeklierdissecties met het oog op omgaan met vaatstructuren.

4. Converteer als een bloeding niet te controleren is met de robot en als je het overzicht verliest, en doe dit liever iets te vroeg dan te laat.

Het belang van het uitvoeren van complexe (cT3b en cT3c) nierchirurgie in hoogvolumecentra werd benadrukt, omdat een dergelijke omgeving leidt tot minder complicaties en een betere oncologische uitkomst op de lange termijn [2].

Behalve de cT3b- en cT3c-niertumoren wordt in Europa een groot deel van de complexe partiële nefrectomieen nog open geopereerd. Voordelen hiervan - besproken door professor Michel - zijn onder andere snelle toegang en controle over het gehele orgaan en de mogelijkheid om snel te kunnen switchen tussen hilus en resectievlak. Verder kan men middels echografie direct het resectievlak markeren en zijn bloedingen sneller onder controle te krijgen.

We kunnen concluderen dat - ondanks de enorme verschuiving naar minimaal-invasieve chirurgie - de open nierchirurgie bij hoogcomplexe casus voorlopig nog niet uit het palet zal kunnen verdwijnen. 


\section{Niersparende chirurgie: wegen de voordelen van partiële nefrectomie op tegen de additionele risico's?}

De EAU-richtlijn adviseert een partiële nefrectomie bij cT1-tumoren, maar wat doen we bij de meer complexe tumoren? In de sessie 'Controversies in renal cancer surgery' werd dit onderwerp besproken in een case based debate.

Dr. Breda bepleitte per definitie een partiële nefrectomie te verrichten als dit technisch mogelijk is, met het oog op nierfunctiebehoud. Bij de radicale nefrectomie (RN) ontwikkelt 10-15\% van de patiënten chronisch nierfalen graad 3 (CKD3; eGFR < $45 \mathrm{ml} / \mathrm{min} / 1,73 \mathrm{~m}$ ), met een negatief effect op de overlevingsduur [3]. Dr. Breda besprak onder andere een recente studie van Bradshaw et al., waarin de RAPN vergeleken werd met MIS-RN bij cT2a-niertumoren [4]. In de RAPN-arm was sprake van significant meer postoperatieve complicaties $(22,2 \%$ vs. $11,1 \% ; p<0,001)$ en positieve snijvlakken ( $8,6 \%$ vs. $2,6 \%$; $p=0,001)$, maar deze hadden geen effect op de vijfjaarsoverleving (76,3 vs. $88,0 \% ; p=0,221$ ) en de vijfjaars ziektevrije overleving $(78,6 \%$ vs. $85,3 \% ; p=0,630)$, ook niet bij een upgrade naar een pT3a-tumor. Wel ontwikkelden minder patiënten in de RAPN-arm de novo CKD3b in vergelijking met de MIS-RN-arm (vijfjaars afwezigheid van de novo CKD3b bij 91,6\% van de patiënten bij RAPN vs. $68,9 \%$ bij MIS-RN; $p<0,001)$.

De conclusie van dr. Breda luidde: kies waar mogelijk voor partiële nefrectomie, ook bij de grotere en meer complexe niertumoren.

\section{Complicaties van nierchirurgie}

In de sessie 'Complications of renal surgery' besprak dr. Michel een review van Cacciamani et al., waarin een overzicht werd gegeven van het intra- en postoperatieve complicatieratio bij open partiële nefrectomie versus RAPN [5]. Deze ratio was lager in de RAPN-groep, voor zowel overall intraoperatieve complicaties (OR $1,81 ; p<0,0001)$ als overall postoperatieve complicaties (OR 1,85; $p<0,00001$ ). Voorspellende factoren voor het ontwikkelen van complicaties zijn leeftijd, ASA-score, preoperatieve anemie, cT2-tumoren, PADUA-score, en open en laparoscopisch versus robotgeassisteerde benadering [6].

Dr. Minervini besprak de complicaties van RAPN aan de hand van een systematische review waarin 176 artikelen en bijna 30.000 procedures werden geëvalueerd [7]. Hij benadrukte dat er sprake is van onderrapportage van intraoperatieve complicaties, omdat een gestandaardiseerd rapportage- en classificatiesysteem ontbreekt. Bij $2,6 \%$ van de ingrepen was sprake van een intraoperatieve complicatie, waarbij bloeding het meest voorkwam (62\%). Dit leidde in $7 \%$ van de gevallen tot een bloedtransfusie. Andere intraoperatieve complicaties waren onder meer vaatletsel (12\%), visceraal letsel (11\%) en ureterletsel (3\%). Dr. Minervini gaf aan dat een ervaren roboturoloog elke complicatie robotgeassisteerd zou moeten kunnen oplossen waarbij een sleutelrol is weggelegd voor exposure. Be- langrijke factoren voor het voorkómen van complicaties zijn zorgvuldige preoperatieve chirurgische planning, een toegewijd operatieteam, enucleatieve resectie op indicatie en een accurate anatomische meerlagige renorrhaphy.

Postoperatief zijn bloeding en urinelekkage de meest voorkomende complicaties. Bij de open partiële nefrectomie heeft urinelekkage een historisch gerapporteerde incidentie van $17,4 \%$ [8]. In het tijdperk van de robotchirurgie ligt dit cijfer nu op ongeveer $1 \%$. Dr. Breda stelde dat niet de robotchirurgie op zich heeft geleid tot een daling in postoperatieve urinelekkage, maar de techniek van accurate meerlagige renorrhaphy. Deze techniek is met de komst van de robotchirurgie geïmplementeerd en wordt door de experts nu ook voor open chirurgie gebruikt.

Een andere veelvoorkomende complicatie bij open chirurgie is de flank bulge. Dit verlies van tonus van de anterolaterale spieren van de buikwand ontstaat bij bijna $50 \%$ van de patiënten door denervatieschade, en gaat in $5-10 \%$ van de gevallen gepaard met een hernia [9]. Deze complicatie leidt tot een afgenomen kwaliteit van leven, afgenomen mobiliteit, slechtere cosmetiek en pijn, en is moeilijk chirurgisch te corrigeren. Patiëntgerelateerde risicofactoren voor het ontstaan van een flank bulge zijn een hoge body mass index (BMI) en constipatie. Chirurgische risicofactoren zijn het gebruik van zelfspreider, falen van identificatie en sparen van de neurovasculaire bundel (subcostale zenuwen), en het en masse sluiten van de wond [10]. Deze aspecten dienen in acht genomen te worden bij open nierchirurgie.

\section{Vaardigheidstraining}

In de discussie die volgde op de sessie 'Complications of renal surgery' werd het belang benadrukt van vaardigheidstraining voorafgaand aan het starten met robotchirurgie. De 'krachten' die je gebruikt tijdens robotchirurgie zijn anders dan bij open chirurgie en als je dit niet van tevoren hebt getraind, kun je makkelijk vaatschade veroorzaken. Uiteindelijk zou vaardigheidstraining vorm moeten krijgen in een gestructureerd curriculum, inclusief certificering.

\section{De toekomst}

In de sessie 'Emerging technologies in partial nephrecto$m y^{\prime}$ werd een nieuwe softwaretechniek gepresenteerd door Porpiglia et al. waarin 3D-augmented reality gebruikt wordt om de kwaliteit van nefronsparende chirurgie te verbeteren. Er is een specifiek systeem ontwikkeld waarin virtuele $3 \mathrm{D}$-data op basis van de CT-scan gefuseerd kunnen worden met het endoscopisch beeld van de DaVinci console. Dit systeem lijkt nuttig te zijn voor de identificatie van intraparenchymale structuren die lastig te visualiseren zijn met alleen echo. In de toekomst zou deze techniek de kwaliteit van de resectie kunnen verbeteren en kunnen leiden tot een vermindering van postoperatieve complicaties. 


\section{Take home messages}

- Ondanks de opkomst van minimaal-invasieve chirurgie blijft er een rol voor open nierchirurgie bij complexe (cT3b- en cT3c-) niertumoren.

- Kies voor partiële nefrectomie als dit technisch mogelijk is, met het oog op het behoud van de nierfunctie.

- Minimaal-invasieve chirurgie, met name de robotgeassisteerde, heeft geleid tot minder intra- en postoperatieve complicaties.

- De sleutelfactoren voor het voorkómen van complicaties bij de RAPN zijn zorgvuldige preoperatieve chirurgische planning, een toegewijd operatieteam, enucleatieve resectie op indicatie en een accurate anatomische meerlagige 'renorrhaphy'.

- Het gebruik van 3D-augmented reality tijdens RAPN zou in de toekomst kunnen leiden tot een kwalitatief betere tumorresectie en minder postoperatieve complicaties.

Open Access This article is distributed under the terms of the Creative Commons Attribution 4.0 International License (http:// creativecommons.org/licenses/by/4.0/), which permits unrestricted use, distribution, and reproduction in any medium, provided you give appropriate credit to the original author(s) and the source, provide a link to the Creative Commons license, and indicate if changes were made.

\section{Bronnen}

1. Larcher A. Were you ready for this level of complexity? Robotic T3 RCC into the IVC - case presentation. EAU20 Virtual, plenaire sessie 5 .

2. Freifeld Y, Woldu SL, Singla N, et al. Impact of hospital case volume on outcomes following radical nephrectomy and inferior vena cava thrombectomy. Eur Urol Oncol. 2019;2(6):691-8.
3. Hamilton ZA, Capitanio U, Lane BR, et al. Should partial nephrectomy be considered 'elective' in patients with stage 2 chronic kidney disease? A comparative analysis of functional and survival outcomes after radical and partial nephrectomy. World J Urology. 2019;37(11):2429-37.

4. Bradshaw AW, Autorino R, Simone G, et al. Robotic partial nephrectomy vs minimally invasive radical nephrectomy for clinical T2a renal mass: a propensity score-matched comparison from the ROSULA (Robotic Surgery for Large Renal Mass) Collaborative Group. BJU Int. 2020;126(1):114-23.

5. Cacciamani GE, Medina LG, Gill T, et al. Impact of surgical factors on robotic partial nephrectomy outcomes: comprehensive systematic review and meta-analysis. J Urology. 2018;200(2):258-74.

6. Mari A, Campi R, Schiavina R, et al. Nomogram for predicting the likelihood of postoperative surgical complications in patients treated with partial nephrectomy: a prospective multicentre observational study (the RECORd 2 project). BJU Int. 2019;124(1):93-102.

7. Cacciamani GE, Tafuri A, Iwata A, et al. Quality Assessment of intraoperative adverse event reporting during 29227 robotic partial nephrectomies: a systematic review and cumulative analysis. Eur Urol Oncol. 2020.

8. Campbell SC, Novick AC, Streem SB, Klein E, Licht M. Complications of nephron sparing surgery for renal tumors. J Urology. 1994;151(5):1177-80.

9. Chatterjee S, Nam R, Fleshner N, Klotz L. Permanent flank bulge is a consequence of flank incision for radical nephrectomy in one half of patients. Urol Oncol. 2004;22(1):36-9.

10. Osman T, Emam A, Farouk A, ElSaeed K, Tawfeek AM, AbuHalima A. Risk factors for the development of flank hernias and bulges following surgical flank approaches to the kidney in adults. Arab J Urol. 2018;16(4):453-9.

dr. A. H. (Heleen) de Vries aios urologie

drs. Patricia J. Zondervan uroloog

prof. dr. Harrie P. Beerlage uroloog , hoogleraar Algemene Urologie 